\title{
Estimating the value of marine resources: a marine recreation case
}

\author{
Oliver H. King \\ Department of Maritime Studies and International Transport, University of Wales \\ College of Cardiff, PO Box 907, Cardiff CF1 3YP, UK
}

\begin{abstract}
This paper discusses the concept of economic value in relation to the appraisal of marine environmental resources. The difficulties of placing monetary values on environmental goods and services for which there is no market are briefly reviewed. $A$ case study is presented which uses contingent valuation to estimate the user value associated with a recreational beach. The paper concludes that economic valuation of environmental resources is feasible and can improve the information basis of public decision-making in marine and coastal environments.
\end{abstract}

\section{INTRODUCTION}

Recent tanker accidents around North America and similar incidents around the coasts of Europe, notably the Exxon Valdez, Haven, Braer and the Aegean Sea, pose a dilemma for policy makers. Maintaining permanent surveillance and a contingency response capability requires the allocation of funds, which could be assigned to other public sectors. During periods of tight Government spending controls, environmental protection programmes constitute ready targets as the public demands that money be channelled into perceived priority areas. ${ }^{1}$

However, the fluctuating importance attached to the environment by governments also reflects the inherent problem facing the public sector, namely quantifying and comparing benefits arising from spending in a diversity of areas and thus maximising the welfare of society. Where a 
policy affects goods and services which are traded in normal markets, changes in prices and income can be linked to consumer behaviour. But in the absence of an observable market how can the benefits of health care, education or protecting the environment be compared?

A solution to this problem involves defining benefits arising from differing sectors in terms of a single unit, money. In the context of recreational benefits arising from natural resources this approach was first suggested in the 1940s. Subsequently there have been growing calls for environmental resources to be valued in economic terms by economists ${ }^{2}$ and ecologists. ${ }^{3}$ This development stems from a belief that unless the value of natural resources is expressed in monetary units it will continue to be assigned a zero value, and will not therefore be incorporated into the decision making process. ${ }^{4}$ This movement has not been without critics and alternative units of measurement, such as energy, have been proposed to value coastal wetlands. ${ }^{5}$ However, such criteria supplant the notion that the individual is the best judge of value, with an alternative objective - ignoring the role of supply and demand. ${ }^{6}$ Money may not be ideal but, as it has been argued, money is a means of systemising and rationalising behaviour. ${ }^{7}$

\section{THE NOTION OF ECONOMIC VALUE}

Before continuing, it is important to clarify the concept of economic value. The components of total economic value of a natural resource are illustrated in Fig. 1. Consider, for example, the economic impacts resulting from an oil spill. Some of these can be measured through observable market transactions, although this approach is normally

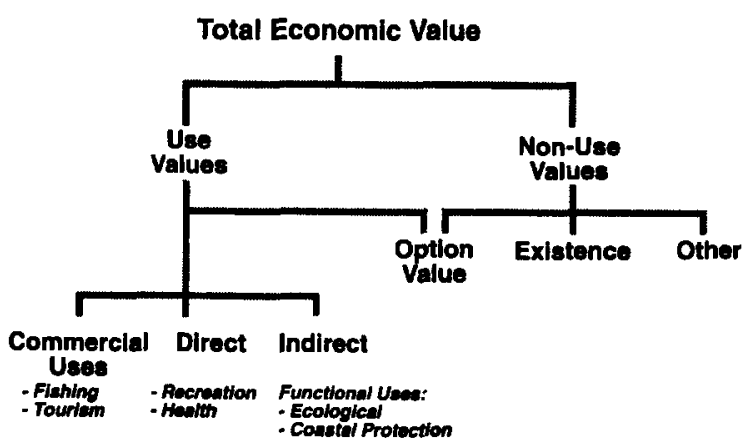

Fig. 1. The components of total economic value. 
limited to commercial activities. For instance, a discharge which reduces fish stocks will eventually lead to a reduction in the income of fishermen (calculated by multiplying the reduction in catch by the market price of the fish). This approach was used to estimate losses incurred by the shellfish industry in the north-west of Spain following the grounding of the oil tanker the Aegean Sea in December $1992 .^{8}$ This approach can also be used to estimate losses incurred in related industries, such as processing and support services. A spill may also discourage tourists from visiting an area, leading to a loss of income for those operating guest houses, hotels and restaurants. This loss can be assumed to be the difference between revenue from a 'normal' season and the affected season. ${ }^{9}$

Other elements are more difficult to quantify. One category of losses, user values, comprises consumptive and non-consumptive benefits. For example, an oil spill which fouls a recreational beach will lead to a loss of consumption benefits arising from the closure of the beach or, if the beach remains open, from a deterioration in beach and water quality. ${ }^{10}$ This includes the losses incurred by recreational beach users, boat-users and fisherman. Similarly, a loss in non-consumptive benefits results from individuals whose enjoyment from viewing the scenery and wildlife has diminished as a consequence of the pollution.

Because marine environmental resources are generally unpriced or 'common' goods there is an absence of observable market transactions with which to estimate value. However, affected users incur a reduction in well-being in three ways: (1) foregoing visits to the polluted shoreline; (2) enjoying a visit to an affected site less; or (3) incurring additional expenses arising from the use of substitute sites. For example, it is estimated that some 245000 visitors avoided Brittany's beaches during the 1978 tourist season following the grounding of the Amoco Cadiz. ${ }^{11}$ This is an extreme illustration but smaller spills have impacts on beach use. The magnitude of these depends upon the frequency of use, the season, the availability of substitute sites, and how long the site is contaminated.

In addition to commercial and current user values two further categories of value exist. The first concerns those individuals who, although not currently using the coastline, wish to preserve the option of doing so at some point in the future. Essentially this option value is the willingness to pay to maintain the natural resource weighted by the probability that the resource will be used at some future date.

The second element represents the loss in benefits suffered by individuals who have no plans to use the beach at any point in time, but for whom knowledge of the injury is sufficient to lower utility. ${ }^{12}$ Such 
values are termed existence or non-use and arise from the notion that individuals who make no use of a particular beach, coast or any natural resource may gain utility from the mere existence of the resource, even if there is no intention to use the resource in the future..$^{13}$ Gains can be categorised under two further headings: vicarious consumption, where utility is derived from knowing about consumption by others; and stewardship, which involves a desire to see resources used in a responsible manner for present and future generations.

Traditionally, there has been some doubt in economics-and considerable doubt elsewhere-as to whether such existence values exist, reflecting the belief that if individuals did obtain utility this would be apparent in their behaviour. Although markets where individuals can express existence values do not exist, many people do indicate vicarious values through voluntary contributions to environmental groups. The majority of individuals supporting a 'Save the Whale' campaign will not have seen a whale in actual life, but are still willing to donate funds. ${ }^{14}$

A further issue arises in defining the relevant population. In determining user benefits it is generally clear who benefits from a resource; however, for existence values this is seldom clear. For example, in estimating existence values for the recent Braer tanker incident, what would have been the appropriate population across which to aggregate total existence value? The residents of the Shetland Islands, Scotland, the UK, Europe? This remains an unresolved issue, but it is arguable that for unique natural resources existence values should be calculated across a wide area. For example, for a site such as the Giant's Causeway in Northern Ireland, which has been declared a UNESCO World Heritage Site, the appropriate market may be the World. Obviously this has great implications when aggregating total value, as deciding whether part of the natural environment is of local, national or international significance is extremely difficult.

In summary, the total economic value of a natural resource is the sum of user and non-user values. Unfortunately identification is only the first step in assisting public policy, and what is required is some means of quantifying each element in monetary terms. Moreover, the validity of the resulting values must be accepted by non-economists. As noted, market prices can only be employed in a limited context, and therefore non-market techniques must be used to quantify the losses. ${ }^{15}$ Regardless of the approach, what is being estimated is the maximum amount that individuals would be willing to pay to secure goods or services. The remainder of this paper briefly outlines the principal non-market techniques and illustrates, with the use of a case study, how recreational use value can be estimated. 


\section{NON-MARKET METHODS OF APPRAISAL}

Two distinct non-market appraisal approaches exist. The first uses demand for complementary goods to estimate demand for natural resources. This includes the travel cost method, which uses journey expenditure and time values, and the hedonic method which typically employs wage or housing data.

The second approach, the contingent valuation method (CVM), involves the construction of hypothetical markets in which natural resources are traded to obtain willingness to pay, or willingness to accept, bids. The CVM is essentially based on the direct elicitation of values from individuals via carefully designed and administered sample surveys. At the heart of this approach is the questionnaire which attempts to develop a plausible market scenario in which bids can be made. Where the exclusion of users from the resource is feasible the scenario may emulate a private market. This commonly takes the form of an entrance charge. Alternatively, a scenario may provide respondents with details of a hypothetical government programme to reduce the probability of any future oil spill. Respondents are then asked how much they would be willing to contribute towards the scheme. ${ }^{16}$ Regardless of the approach, the scenario must be plausible and relevant. This demands that sufficient information be included to allow the respondent to make an informed bid.

Contingent valuation remains a controversial technique and many critical issues exist. However, estimates from CVM studies compare favourably with those arising from other non-market methodologies. Moreover, CVM has proved particularly flexible in valuing environmental commodities for which existing non-market approaches have failed. ${ }^{17}$ It was for this reason that the technique was chosen for use in the following study.

\section{THE CASE STUDY}

The aim of this study was to apply the CVM to estimate the value of recreational beach use and to assess the economic benefits of improved water and beach quality associated with the prevention of oil pollution. This was attempted by estimating aggregate willingness to pay for beach use $\left(\mathrm{WTP}_{\mathrm{rst}}\right)$. To illustrate the methodology the remainder of the section is divided into four further sections: 4.1 provides background information on the case study; 4.2 outlines the underlying demand function; 4.3 describes the format of the questionnaire; and 4.4 reports the results. 


\subsection{Background to the resort of Eastbourne}

The town of Eastbourne is a popular seaside resort situated on the English Channel (see Fig. 2). The resort attracts a variety of users, having direct road and rail links to London, a traditional seafront and promenade complex and well maintained beaches. The majority of visitors originate from the south-east of England. Individuals can be divided into four groups: (1) promenade users; (2) attraction users; (3) beach recreationalists; and (4) water users.

The coastline is characterised by shingle beaches, large stretches of which are extensively groyned to prevent the loss of material. At high tide only a narrow shingle strip, typically $5-8 \mathrm{~m}$, is available for recreational activity. At low tide sand is exposed beyond the extent of the groynes. To the west of the town are the famous white chalk cliffs of Beachy Head. This stretch of shore is designated as part of the English Heritage Coastline ${ }^{18}$ and contains a non-statutory marine conservation area.

Shipping concentration in the waters off Eastbourne is high, reflecting the proximity of the Dover Straits. Apart from the occurrence of isolated tar patches on the beaches, the resort has had minimal experience with oil contamination - the last incident involved a minor

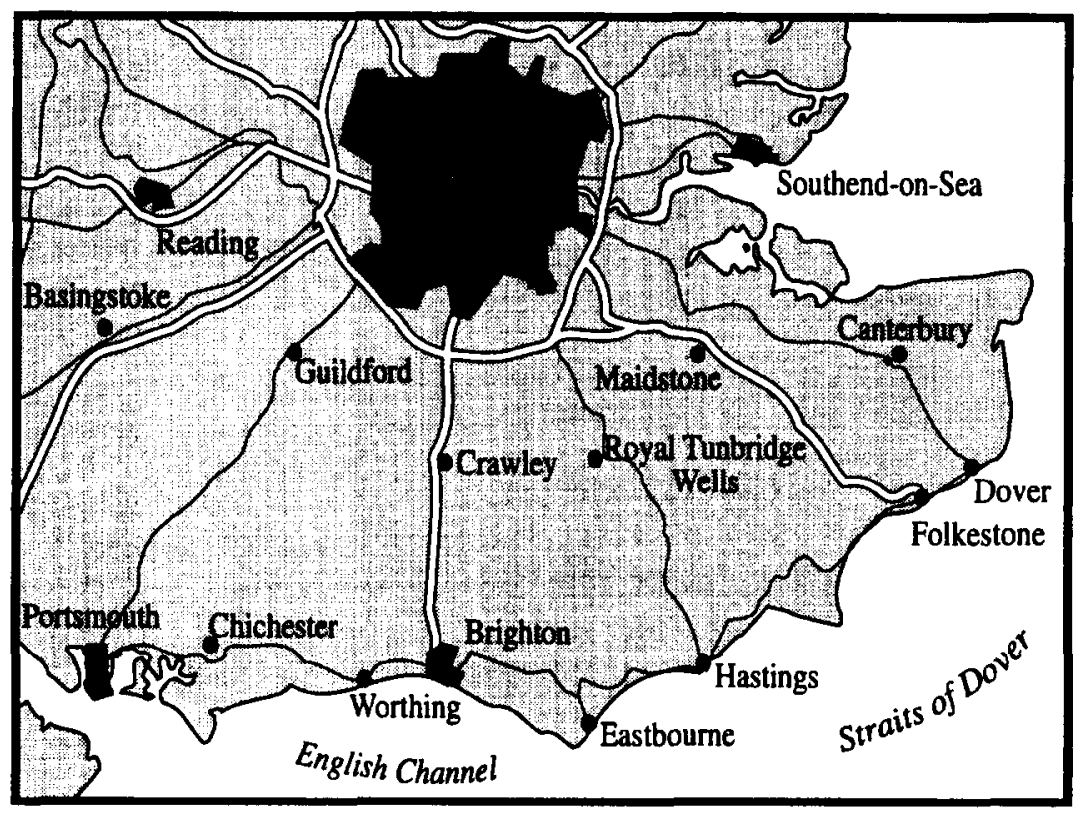

Fig. 2. The south-east of England. 
spill in 1988 outside the tourist season. However, the Sussex coast has been subjected to more serious incidents, with chemical drums being washed ashore and leading to the closure of beaches. Given this background it was felt that most respondents would be aware of the possible impact of pollution on the resort.

\subsection{The model}

In formulating a predictive model of recreational demand for WTP for beach days $\left(\mathrm{WTP}_{\mathrm{rst}}\right)$ several independent variables were highlighted by the literature. In addition to basic socio-economic characteristics, such as sex and age, previous contingent valuation studies have shown that income, previous knowledge of the resource and awareness of environmental issues influence WTP bids. ${ }^{19}$ The WTP function was therefore specified as:

\section{WTP $_{\text {rst }}=($ INCOME,AGE,SEX,FREQ,ENV,RATING,GRPCHILD)}

where INCOME = total household yearly income; $\mathrm{AGE}=$ age of the respondent; $S E X=$ dummy variable; $F R E Q=$ average number of visits per year for residents, number of previous visits to site for visitors; $\mathrm{ENV}=$ composite dummy variable incorporating membership of environmental/conservation body and participation in outdoor recreational activity; RATING = integral value between 1 and 10 chosen from scale; and GRPCHILD = dummy variable indicating the inclusion of a child in a visiting group.

\subsection{The questionnaire}

This was divided into four sections, which: (1) provided an introduction and explanation of purpose; (2) sought information on visitor type, travel patterns and familiarity with the seafront; (3) outlined the scenario and the market definition for WTP for beach days and WTP for oil pollution avoidance; and (4) socio-economic questions, including membership of environmental/conservation groups, age, education, sex and household income.

Interviews were conducted in person as this approach offers the greatest opportunity to motivate a respondent in the face of difficult questioning and also allows additional questions to be asked where unclear responses are elicited. ${ }^{20}$

Because the possibility of exclusion from the Eastbourne seafront existed, a quasi-private market was chosen as the appropriate mechanism to extract willingness to pay bids, i.e. ticket charge for beach use. 
Respondents were reminded of the existence of substitute coastal sites and then asked for a bid. The payment vehicle involved open-ended questioning, asking the respondent to state the maximum sum. The payment vehicle was specified as:

I am trying to find out what value you place on being able to use Eastbourne seafront/beach. To do this imagine that you had to pay a daily entrance fee to use the seafront and beaches. What then would be the maximum amount that you would be willing to pay for a day ticket to use this beach in its current condition, per person, per visit?

\subsection{Results}

The main survey was conducted in August 1993 during the peak tourist period. While a sample size of at least $500-600$ in size is generally recommended to obtain estimates of WTP within $95 \%$ of the mean, this was beyond the means of this survey. ${ }^{21}$ Instead a total of 179 individuals was randomly selected providing a total of 167 responses.

The overall results are displayed in Table 1 . Table 2 illustrates bids by visitor category. The mean $\mathrm{WTP}_{\mathrm{rst}}$ was 11.78 (CND\$3.68). In addition to the WTP $_{\text {rst }}$ function the study also attempted to estimate willingness to pay for a reduction in the frequency of oil spills and this resulted in a mean value of $£ 1.41$ (CND\$2.92).

The payment vehicle and the scenario plausibility appeared to be generally accepted. The percentage of zero bidders is low when compared with other studies. ${ }^{22}$ However, of those respondents reporting zero WTP bids, $80 \%$, when questioned further, implied that their response represented a protest. The majority of such bidders objected to the concept of a ticket charge, arguing that beaches are a public good and pollution control and clean-up is the responsibility of government.

TABLE 1

Willingness to pay for recreational beach use

\begin{tabular}{|c|c|c|c|c|c|}
\hline \multicolumn{2}{|c|}{ Total sample } & \multirow[t]{2}{*}{ Sample size } & \multirow{2}{*}{$\begin{array}{l}\text { Percent zero } \\
\text { bidders }\end{array}$} & \multicolumn{2}{|c|}{ Non-zero bidders } \\
\hline Mean & Median & & & $\begin{array}{c}\text { Mean } \\
(\boldsymbol{f})\end{array}$ & $\begin{array}{l}\text { Median } \\
(£)\end{array}$ \\
\hline $\begin{array}{c}£ 1.78 \\
\text { CND } \$ 3.68 \\
(1.21)\end{array}$ & $\begin{array}{c}£ 1.50 \\
\text { CND\$3.11 }\end{array}$ & 167 & 8.4 & $\begin{array}{c}£ 1.93 \\
\text { CND } \$ 4.00 \\
(1.14)\end{array}$ & $\begin{array}{c}£ 2.00 \\
\text { CND\$4.14 }\end{array}$ \\
\hline
\end{tabular}

Note: Standard deviations in parentheses $(£)$. 
TABLE 2

Willingness to pay for recreational beach use by visitor type

\begin{tabular}{|c|c|c|c|c|c|}
\hline \multirow[t]{2}{*}{ User type } & \multicolumn{2}{|c|}{ Total sample } & \multirow[t]{2}{*}{ Sample size } & \multicolumn{2}{|c|}{ Non-zero bidders } \\
\hline & Mean & Median & & Mean & Median \\
\hline Resident & $\begin{array}{c}\mathfrak{f 2 . 0 2} \\
\text { CND } \$ 4.18 \\
(1.31)\end{array}$ & $\begin{array}{c}\mathfrak{2} 2.00 \\
\mathrm{CND} \$ 4.14\end{array}$ & 58 & $\begin{array}{c}£ 2.21 \\
\text { CND } \$ 4.57 \\
(1.20)\end{array}$ & $\begin{array}{c}£ 2.00 \\
\text { CND } \$ 4.14\end{array}$ \\
\hline Day visitors & $\begin{array}{c}£ 1.61 \\
\text { CND } \$ 3.33 \\
(1.21)\end{array}$ & $\begin{array}{c}£ 1.50 \\
\mathrm{CND} \$ 3.11\end{array}$ & 34 & $\begin{array}{c}£ 1.83 \\
\text { CND } \$ 3.79 \\
(1.13)\end{array}$ & $\begin{array}{c}£ 1.50 \\
\text { CND } \$ 3.11\end{array}$ \\
\hline Staying visitors & $\begin{array}{c}£ 1.67 \\
\text { CND\$3.46 } \\
(1.12)\end{array}$ & $\begin{array}{c}£ 1.50 \\
\text { CND\$3.11 }\end{array}$ & 75 & $\begin{array}{c}£ 1.77 \\
\text { CND } \$ 3.66 \\
(1.07)\end{array}$ & $\begin{array}{c}£ 1.50 \\
\text { CND } \$ 3.11\end{array}$ \\
\hline
\end{tabular}

Note: Standard deviations in parentheses $(\mathfrak{f})$.

These criticisms point to an inherent susceptibility of ticket based payment mechanisms which can only be evaluated on an individual basis through the examination of zero bids.

To place this result in perspective it is useful to estimate the aggregate annual use value of Eastbourne's beaches. This is calculated as the product of mean WTP $_{\mathrm{rst}}$ and the total number of user beach days. Using existing information the total annual number of visitor days was estimated at 2.6 million. $^{23}$ The aggregate annual recreational use value was therefore calculated to be of the order of $£ 4.5$ million. This value should be considered as a lower bound because it excludes option value and also non-use value, which are likely to be significant.

\section{CONCLUSION}

This study adds to the growing body of literature which indicates that the valuation of environmental goods and services is possible. Moreover, it demonstrates that the contingent valuation method is a suitable approach to estimating the values associated with marine resources. Asking individuals to place a value on the use of beach amenities is a difficult and unfamiliar task, but on the basis of this study the ability and willingness of respondents to undertake this task appears high.

Placing a monetary value on marine resources has important implications in two areas. The first concerns the incorporation of such values 
into the public decision making. Decisions regarding activities and developments in the coastal area have traditionally been based on informal judgement or financial analysis. However, this approach does not lead to an optimum management strategy. To achieve the latter requires information on the social costs and benefits in order to make an explicit trade-off - in other words, cost benefit analysis. Three areas would benefit from such an approach.

1. Management of marine environmental resources. The environmental benefits provided by marine resources, such as beaches and coral reefs, include many non-marketed goods and services. Traditionally these components have not been quantified in monetary terms which has led to marine resources being undervalued. For example, Hodgson \& Dixon used cost benefit analysis to evaluate alternative development programs in the Philippines. They concluded that over a 10 year period reef fisheries and tourism would generate US\$41 million more than logging the adjacent forests. ${ }^{24}$

2. Regulation of marine industries. This refers to industries whose activities impact upon the marine environment, such as shipping, dredging and oil and gas production. The Canadian Coast Guard has led the way in the shipping field with a pioneering study in 1984. This study applied cost benefit analysis to provide a qualitative analysis of the need for, and benefits of, vessel traffic schemes. ${ }^{25}$ The US Coast Guard has also undertaken similar studies, ${ }^{26}$ particularly in relation to the obligations of the Oil Pollution Act of $1990 .{ }^{27}$ In the UK and the European Union such an explicit evaluation of environmental marine damage is only now beginning to take place.

3. Compensation arrangements following oil pollution. ${ }^{28}$ While in economic terms the total value of a resource is the sum of the services it supports, this is currently not the position adopted in the international oil pollution compensation framework. ${ }^{29}$ Instead damages are restricted to property interests, which means that while there has been no problem paying out claims for direct damages-such as fish in fish farms, coastal property, boats and nets-other user and non-user benefits have been excluded.$^{30}$ The absence of a universally accepted methodology for placing a value on environmental damages is increasingly leading to a wide-and often unsubstantiated-variation in the size of claims. ${ }^{31}$

However, two arguments are commonly cited to support the current 
regime. Firstly, as already noted there is the problem of estimating such damages. Secondly, there is the question of to whom such compensation payments should be made, since the large number of individuals involved precludes single payments. The obvious solution is for compensation to be paid to governments, acting in their role of custodians of common resources and maximisers of national welfare. However, this is not an ideal scenario for it is a matter of debate whether governments fulfil either role. An alternative might be the creation of national bodies to receive settlements and charged with maintaining the quality and provision of natural resources.

In conclusion, by combining estimates of use and increasingly existence values with existing data on clean-up and restoration costs, a more accurate assessment of the true social value of marine resources will emerge. This in turn should be reflected in the management and regulation of activities which impact upon the marine environment.

\section{REFERENCES}

1. This discussion forms part of a wider project to place a monetary value on shipping casualties. This work is sponsored by the UK Engineering and Physical Sciences Research Council.

2. Pearce, D. W. \& Markandya, A., Environmental Policy Benefits Monetary Valuation. OECD, Paris, 1988.

3. Helliwell, D. R., Valuation of Wildlife Resources. Regional Studies, 3 (1969) 47-57.

4. Green, C. H. \& Tunstall, S. M., Is the Economic Evaluation of Environmental Resources Possible? Journal of Environmental Management, 33 (1993) 123-41.

5. Shabman, L. A. \& Batie, S. S., A Reply to the Rebuttal of 'Economic Value of Natural Coastal Wetlands: A Critique'. Coastal Zone Management, 5 (1978) 243-4.

6. Desvousges, W. H., Dunford, R. W. \& Domanico, J. L., Measuring Natural Resource Damages: Final Report. American Petroleum Institute, Washington, DC, 1989.

7. Mitchell, W. C., Types of Economic Theory, ed. Joseph Dorfman. Augustus M. Kelly, New York, 1969, Volume 2.

8. Total claims in respect of shellfish losses currently amount to $£ 44$ million, based on 1991 sales. Aegean Sea Compensation. Marine Pollution Bulletin, 26 (1993) 235.

9. Gringalunas, T. A., Anderson, R. C., Brown, G. M., Congar, R., Meade, N. F. \& Sorensen, P. E., Estimating the Cost of Oil Spills: Lessons from the Amoco Cadiz Incident. Marine Resource Economics, 2 (1986) 239-62.

10. An oil spill may conceivably lead to an increase in utility of "catastrophe 
junkies' or some members of the press. However this gain is largely outweighed by losses for the majority of the population.

11. Assessing the social costs of oil spills: the Amoco Cadiz case study. US Department of Commerce, National Oceanographic and Atmospheric Administration, Washington, DC, 1983.

12. Krutilla suggested that non-use values occur because individuals may be willing to pay: to preserve the option to use the site at a future date (option value); to preserve the resource for future generations (bequest value); or because utility is derived from simply knowing the resource exists in a good state (existence or non-use value). Krutilla, J. V., Conservation Reconsidered. American Economic Review 57 (1967) 78796.

13. Krutilla, J. V. \& Fisher, A. C., The Economics of Natural Environments: Studies in the Valuation of Commodity and Amenity Resources. The John Hopkins University Press for Resources for the Future, Baltimore, 1975.

14. This is not an intrinsic value, for economic theory is anthropocentric in that whales only have 'value' if humans are prepared to pay for them.

15. For a review of these techniques see Smith, V. K., Nonmarket Valuation of Environmental Resources: An Interpretative Appraisal. Land Economics, 69 (1993) 1-26. Alternatively, for marine resources see King, O. H., Measuring Demand for Marine Resources: Theory and Practice. Occasional Paper 8, Department of Maritime Studies and International Transport, UWCC, 1993.

16. This process may take three forms. The most simple approach involves individuals being asked for a maximum sum. Alternatively, the sequential bidding method asks respondents whether they would pay a stated sum, and in response to a 'yes' bid the sum is increased until the respondent replies 'no'. The final approach is close-ended questioning, or the referendum model, in which the individual is asked whether they would pay a stated sum.

17. Carson, R. T., Constructed Markets. In Measuring Demand for Environmental Quality, ed. J. B. Braden \& C. D. Kolstad. North-Holland, 1989.

18. Heritage Coast refers to 44 designated areas around the coasts of England and Wales which are noted for their high scenic quality.

19. McConnel, K. E. \& Weaver, T. F., Setting Capacity Standards for Saltwater Beaches. University of Rhode Island, Agricultural Experiment Station Bulletin 426, Contribution 1831, 1977; Penning-Rowsell, E. C., Green, C. H., Thompson, P. M., Coker, A. M., Tunstall, S. M., Richards, C. \& Parker, D. J., The economics of coastal management. Belhaven Press, London, 1992; Silberman, J., Gerlowski, D. A. \& Williams, N. A., Estimating Existence Value for Users and Nonusers of New Jersey Beaches. Land Economics, 69 (1992) 225-36.

20. The pilot survey identified a major problem with the original survey specification. Respondents were shown a photograph of a beach with light oil pollution with a supporting statement outlining the possible impact on beach and water users. Individuals were then asked to indicate possible changes in: enjoyment associated with a visit; frequency of use; and willingness to pay for a beach day. The influence of photographs on WTP bids has been noted and in this case proved to be strongly negative, 
causing all respondents to return zero WTP for beach use bids. See Mitchell, R. C. \& Carson, R. T., Using Surveys to Value Public Goods: The Contingent Valuation Method. Resources for the Future, Washington, DC, 1989.

21. See Penning-Rowsell et al., Ref. 19.

22. For example, one study reported $35-55 \%$ zero bidders. See Silberman et al., Ref. 19.

23. Eastbourne Tourism Survey 1990. Volume 2: Visitor Profiles. Eastbourne Borough Council, 1992.

24. Hodgson, G. \& Dixon, J. A., Logging versus fisheries and tourism in Palawan. Occasional Paper 7, East-West Environment and Policy Institute, Honolulu, 1988. Spurgeon similarly considered the economic value of coral reefs, see Spurgeon, J. P. G., The Economic Valuation of Coral Reefs. Marine Pollution Bulletin, 24 (1992) 529-36.

25. For an appraisal of environmental damages in this context, see Quon, T. \& Everson, P., Assessing the Benefits and Costs of VTS: A Canadian Example with Emphasis on Risk Assessment and Environmental Protection. Paper presented at Vessel Traffic Symposium, Vancouver, 1992.

26. Maio, D. J., Ricci, R. C., Rossetti, M., Schwenk, J. \& Liu, T., Port Needs Study (Vessel Traffic Services Benefits): Volume 1 - Study Report. United States Coast Guard, US Department of Transportation, Washington, DC, 1991.

27. For example, Mercer Management Consulting Inc., Interim Regulatory Impact Analysis for Vessel Response Plans. Report for US Department of Transportation, 1993.

28. In the US the economic appraisal of pollution damages is already carried out under the Comprehensive Environmental Response, Compensation and Liability Act of 1980 (CERCLA). For a review of the methodologies used, see US Department of the Interior, Measuring Damages to Coastal and Marine Natural Resources. Concepts and Data Relevant for CERCLA Type A Damage Assessments. Volume 1. CERCLA 301 Project, Washington, DC, 1987.

29. Redgwell, C., Compensation for oil pollution damage. Marine Policy, 16 (1992) 90-8.

30. Elferink, A. E., Liability and Compensation of Oil Pollution Damage to the Environment: Is the Existing International Regime Satisfactory'. North Sea Monitor. March (1993) 8-11.

31. This limited compensation regime does appear to be under pressure, principally in the wake of the compensatory arrangements provided for under the Oil Pollution Act of 1990, see Ref. 29. This Act, in addition to user values, recognised the concept of existence or non-use values as a legitimate element to be used for judicial or administrative determination of natural resource damages. See Arrow, K. \& Solow, R., Natural Resource Damage Assessments Under the Oil Pollution Act of 1990. Federal Register, 58 (1993) 4601-14. 